\title{
STRUCTURAL AND OPTOELECTRONIC PROPERTIES OF SPUTTERED COPPER (I) CHLORIDE
}

\author{
Gomathi Natarajan ${ }^{1}$, Lisa O’Reilly ${ }^{1}$, Stephen Daniels ${ }^{1}$, David C. Cameron ${ }^{2}$, \\ Patrick J.McNally ${ }^{1}$, Olabanji Lucas ${ }^{1}$, Alec Reader ${ }^{3}$, Anirban Mitra ${ }^{4}$, Louise Bradley ${ }^{4}$ \\ ${ }^{1}$ Nanomaterials Processing Laboratory (NPL), Dublin City University, Dublin-9, Ireland \\ ${ }^{2}$ Advanced Surface Technology Research Laboratory (ASTRaL), Mikkeli Research Centre, \\ Lappeenranta University of Technology, PL181, 50101 Mikkeli, Finland. \\ ${ }^{3}$ Innos Ltd., University of Southampton, Highfield, Southampton, SO17 1BJ, U.K. \\ ${ }^{4}$ Optoelectronics Laboratory, Trinity College, Dublin 2, Ireland
}

\begin{abstract}
Copper (I) Chloride is a wide band gap semiconductor with great potential for silicon-based optoelectronics due to the fact that is closely lattice matched with silicon. This work examines the deposition of $\mathrm{CuCl}$ thin films by magnetron sputtering on silicon and glass substrates. Film structural and morphological properties are studied with X-ray diffraction and atomic force microscopy. Optical absorbance and luminescence spectra of $\mathrm{CuCl}$ thin films are analysed in order to study the excitonic features. The influence of deposition process parameters and post annealing on the film properties are also reported.
\end{abstract}

Keywords: $\mathrm{CuCl}$, Magnetron sputtering, XRD, Luminescence, exciton

\section{INTRODUCTION}

Group III nitrides and their variants have been dominant for ultraviolet and blue optical devices and are generally grown on sapphire or silicon carbide substrates. A large lattice mismatch between the film and the substrate results in very high dislocation densities and reduces the emission lifetime and reliability of the device. Any potential device that makes use of silicon as a substrate can more readily be integrated into industrial processes and exploit current technology. Epitaxial growth of GaN layer on silicon substrates has been demonstrated by few research groups. ${ }^{1-3}$ However, large mismatch of the lattice constant $(\sim 17 \%)$ and thermal expansion coefficient $(\sim 57 \%)$ between $\mathrm{GaN}$ and $\mathrm{Si}$, and the difference in crystal structures (GaN: hexagonal, $\mathrm{Si}$ : cubic) cause dislocations at the interface, which ultimately reduce the device quality.

The present investigation reports the growth and analysis of cubic zinc blende - $\gamma$-Copper (I) Chloride $(\mathrm{CuCl})$ which has a small lattice mismatch of less than $0.4 \%$ with Silicon. $\mathrm{CuCl}$ has been performing as a model material for many studies based on absorption and emission excitonic spectroscopy, as the exciton biding energy is very high $(190 \mathrm{meV})^{4} \mathrm{which}$ makes it possible to realize high density exciton states in wide temperature ranges.

Epitaxial growth of $\mathrm{CuCl}$ thin films on various substrates such as $\mathrm{GaP}^{5}, \mathrm{MgO}^{6-8}$ and $\mathrm{CaF}_{2}^{8,9}$ by molecular epitaxy and thermal evaporation ${ }^{10}$ has been reported. One research group has analysed the growth of $\mathrm{CuCl}$ on $\mathrm{Si}$ and $\mathrm{GaAs}$ focusing on the interface reactions. ${ }^{11} \mathrm{We}$ have also recently reported the growth of polycrystalline $\mathrm{CuCl}$ films on $\mathrm{Si}$ by vacuum evaporation. ${ }^{12}$ Even though sputtering is one of the potential techniques of PVD, reports of sputter deposition of $\mathrm{CuCl}$ are hardly found in the literature. However a few other copper halides such as $\mathrm{CuI}$ and $\mathrm{CuBr}$ have been grown successfully by this technique. ${ }^{13,14}$ In this paper, we report on the growth of $\mathrm{CuCl}$ thin films by the sputtering technique, and the influence of deposition and post annealing parameters on the sputtered film properties. 


\section{EXPERIMENTAL ARRANGEMENT}

$\mathrm{CuCl}$ thin films were deposited using RF Magnetron Sputtering on to the $\mathrm{Si}(111)$ and soda-lime glass substrates, ultrasonically cleaned with acetone, trichloroethylene, methanol and deionised water. The target was prepared from $97 \%$ $\mathrm{CuCl}$ powder using a hydraulic press with $200 \mathrm{~kg} / \mathrm{cm}^{2}$ pressure and 60 seconds hold on time, bonded to a copper backing plate. Prior to deposition, the target was presputtered for 10 minutes. The substrates were placed at three different positions: $3 \mathrm{~cm}, 6 \mathrm{~cm}$ and $9 \mathrm{~cm}$ from the target and the deposition was performed under constant conditions for 30 minutes. The other deposition conditions are tabulated below in table.1.

\begin{tabular}{ll}
\hline Target diameter & 2 inches \\
RF power density & $0.5 \mathrm{~W} / \mathrm{cm}^{2}$ \\
Sputtering gas & $100 \%$ Argon \\
Base pressure & $\sim 1 \times 10^{-7} \mathrm{mbar}$ \\
Ar Pressure & $2 \times 10^{-3} \mathrm{mbar}$ \\
Substrate temperature & $\sim 30^{\circ} \mathrm{C}$ (no intentional heating) \\
\hline
\end{tabular}

Table 1: Sputtering Conditions

Post annealing was carried out at various temperatures in a nitrogen atmosphere for 30 minutes to improve the crystalline quality of the as-deposited films. Crystallinity of the $\mathrm{CuCl}$ films on glass was examined by $\mathrm{X}$-ray diffraction (XRD) analysis using Bruker D8 advance instrument with $\mathrm{Cu} \mathrm{k}_{\alpha}$ radiation with the wavelength of $1.54 \AA$. The surface morphology analysis was done using a Pacific Nanotechnology Nano-R atomic force microscope. Microstructural and compositional studies were performed with LEO Stereoscan 440 scanning electron microscope and Princeton Gamma tech energy dispersive $\mathrm{X}$-ray analyser with a $\mathrm{Si}(\mathrm{Li})$ detector. Film composition was analysed relative to the target with an optimized accelerating voltage of $14.47 \mathrm{keV}$ and probe current of $3 \mathrm{nA}$. Optical absorbance and transmittance spectra were taken in the visible and ultra violet regions using Perkin Elmer Lambda $40 \mathrm{UV} / \mathrm{Vis}$ spectrometer. $\mathrm{An}^{+} \mathrm{Ar}^{+}$laser of $244 \mathrm{~nm}$ wavelength was used to excite photoluminescence (PL) in $\mathrm{CuCl}$ films on silicon substrates at a range of temperatures and the emission spectra were collected by a liquid nitrogen cooled CCD camera.

\section{RESULTS AND DISCUSSION}

Table 2 shows the dependence of film composition on the target to substrate distance $\left(\mathrm{d}_{\mathrm{ts}}\right)$ for the films deposited on Silicon substrates. The basic composition of the target was almost stoichiometric for the optimized accelerating voltage of $14.47 \mathrm{kV}$. The precision of the $\mathrm{Si}(\mathrm{Li})$ detector was $\pm 2 \%$ relative.

\begin{tabular}{ccc}
\hline Sample & $\mathrm{Cu}$ (atomic \%) & $\mathrm{Cl}$ (atomic \%) \\
\hline Target & 49.14 & 50.86 \\
$\mathrm{~d}_{\mathrm{ts}}=3 \mathrm{~cm}$ & 40.75 & 59.25 \\
$\mathrm{~d}_{\mathrm{ts}}=6 \mathrm{~cm}$ & 48.06 & 51.94 \\
$\mathrm{~d}_{\mathrm{ts}}=9 \mathrm{~cm}$ & 47.92 & 52.08 \\
\hline
\end{tabular}

Table 2: Dependence of film composition on the target to substrate distance

The composition of the samples deposited with $\mathrm{d}_{\mathrm{ts}}$ of $6 \mathrm{~cm}$ and $9 \mathrm{~cm}$ were almost close to that of the target (with in the error limit), whereas a large deviation was observed for the film with $\mathrm{d}_{\mathrm{ts}}$ of $3 \mathrm{~cm}$. This deviation may be due to the higher energy of the depositing atoms for the substrate close to the target. 
The energy of sputtered particles obeys the Thompson distribution and is affected by the binding energy of the atoms in the target. ${ }^{15}$ A value of $5 \mathrm{eV}$ was used as the most likely energy of the sputtered atoms for both $\mathrm{Cu}$ and $\mathrm{Cl}$. As the sputtered atoms leave the target they undergo collisions with the background Ar gas, lose their energy and become thermalised. This is briefly explained by a simple model of thermalization proposed by Westwood ${ }^{16}$. The sputtered atoms are thermalised after undergoing a number of collisions with the background gas. The number of collisions, $n$, is given by the equation

$$
n=\frac{\ln \left(E_{\text {in }} / E_{g}\right)}{\ln \left(E / E^{\prime}\right)}
$$

Where $E_{\text {in }}$ is the energy of the sputtered atom as it leaves the target, $E_{g}$ is the energy of the thermalised atom and $E^{\prime} / E$ is the fractional energy loss of the sputtered atom if it is $E$ and $E^{\prime}$ before and after collision. Using these equations, the average number of collisions undergone by $\mathrm{Cu}$ and $\mathrm{Cl}$ atoms before thermalisation is 6 and 5 respectively. The perpendicular distance from the target they will travel before thermalisation can be estimated by

$$
d=n \lambda\langle\cos \theta\rangle-----(2)
$$

Where $\langle\cos \theta\rangle$ is the average scattering angle per collision and $\lambda$ is the mean free path, which is $3.3 \mathrm{~cm}$ in this case. This gives a thermalisation distance of around $20 \mathrm{~cm}$ for $\mathrm{Cu}$ and $17 \mathrm{~cm}$ for $\mathrm{Cl}$. It is clear that at the surface of the substrates placed within these distances, the $\mathrm{Cu}$ atoms will have on average a higher energy than the $\mathrm{Cl}$ atoms.

When the substrate is kept within the thermalization distance as well as within the mean free path, the sputtered neutrals reach the substrate with high energy (almost with their initial energy) with very few collisions. In addition, the surface atoms may also experience some collisions and energy transfer from the high energy reflected neutral Ar atoms from the target. The higher energies make them more mobile and it is more likely that free atoms will be desorbed. In the surface migration of $\mathrm{Cu}$ and $\mathrm{Cl}$ atoms present on the growing surface, the bonding of copper to two chlorine atoms as $\mathrm{CuCl}_{2}$ is more favourable compared to the formation of $\mathrm{CuCl}$ according to the bond enthalpies. $\left(\triangle \mathrm{H}\left(\mathrm{CuCl}_{2}\right)=-186 \mathrm{kJmol}^{-1}\right.$, $\left.\Delta \mathrm{H}(\mathrm{CuCl})=-117 \mathrm{kJmol}^{-1}\right) \cdot{ }^{17}$ If the fluxes of $\mathrm{Cu}$ and $\mathrm{Cl}$ atoms from the target are equal, it is likely that any $\mathrm{Cl}$ atoms on the surface will bond with $\mathrm{Cu}$ whereas some $\mathrm{Cu}$ atoms may remain unbonded. These unbonded $\mathrm{Cu}$ atoms will more easily desorb from the substrate. This may explain the $\mathrm{Cu}$ deficiency in the film deposited with $\mathrm{d}_{\mathrm{ts}}$ of $3 \mathrm{~cm}$. The presence of the $\mathrm{CuCl}_{2}$ phase is indicated from the absorbance spectra (figure 2).

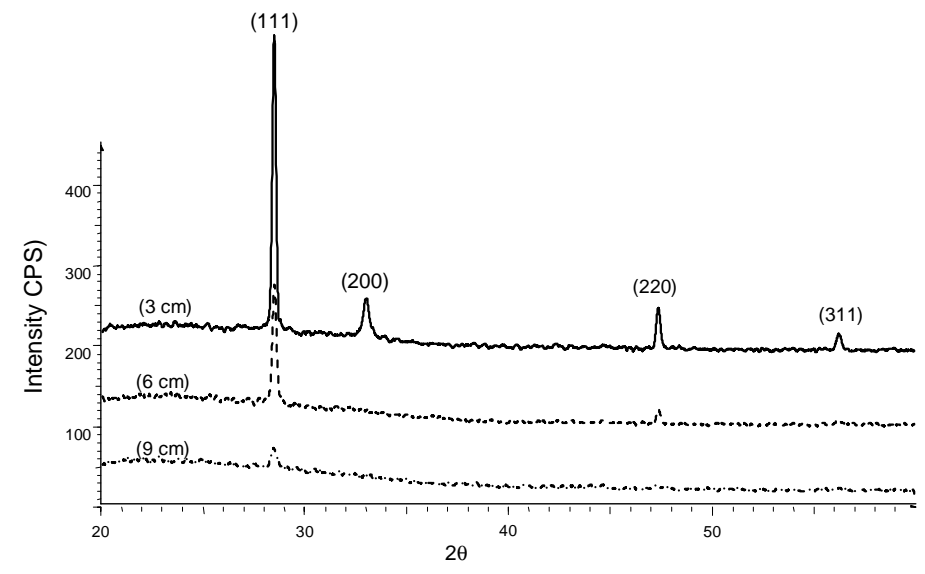

Figure 1: XRD spectra of $\mathrm{CuCl}$ films sputtered at different $d_{t s}$

The growth of evaporated $\mathrm{CuCl}$ film on an amorphous glass substrate is strongly oriented with its preferred direction of $<111>$ perpendicular to the substrate. ${ }^{12} \mathrm{X}$-ray diffraction spectra of $\mathrm{CuCl}$ films on glass deposited with various target to substrate distances are shown in figure 1, measured using $\theta-2 \theta$ geometry. Sputtered $\mathrm{CuCl}$ films also show a strong (111) diffraction peak at 20 28.5, with smaller reflections due to the other planes. From the diffraction patterns it is clearly seen that the intensity of the (111) peaks increases as $d_{t s}$ decreases. This decrease in intensity is not due to film thickness variations, which were around $20 \%$. 
Another noticeable feature is the appearance of (200) peak at $2 \theta \sim 33$ in the $\mathrm{CuCl}$ film sputtered at $3 \mathrm{~cm}$ from the target. This is normally not observed in the $\mathrm{CuCl}$ films evaporated on glass. ${ }^{12}$ Disorder produced by the deficiency of copper and the presence of $\mathrm{CuCl}_{2}$ species, as indicated by the EDX and spectroscopic analysis respectively could be the reasons for the appearance of (200) peak in this sample.

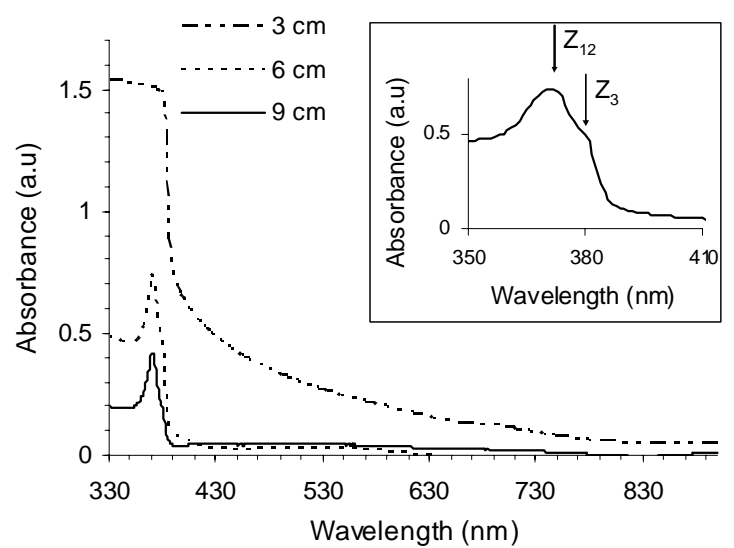

Figure 2: Absorbance spectra of $\mathrm{CuCl}$ on glass with different $d_{t}$

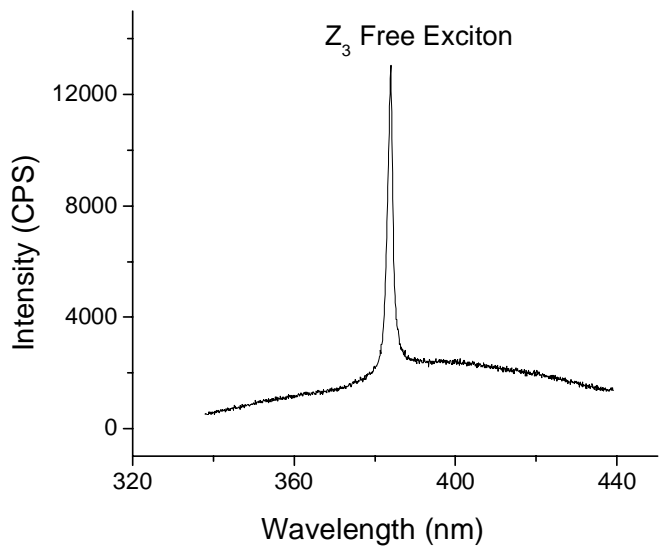

Figure 3: PL spectra of $\mathrm{CuCl}$ on $\mathrm{Si}$ at $10 \mathrm{~K}$

Room temperature absorbance spectra of the samples with $\mathrm{d}_{\mathrm{ts}} 6 \mathrm{~cm}$ and $9 \mathrm{~cm}$ have two peaks at $372 \mathrm{~nm}$ and $382 \mathrm{~nm}$ which are $Z_{12}$ and $Z_{3}$ excitons respectively, which are followed by a flat absorption.(Figure 2) $Z_{12}$ is the bound exciton made up of a $\Gamma_{8}$ hole and a $\Gamma_{6}$ conduction electron, and $Z_{3}$ is the free exciton which has a hole from $\Gamma_{7}$ state and an electron from $\Gamma_{6}$ state. $^{18}$ These exciton peak positions are in a very good agreement with the previous reports. ${ }^{19,20}$ The sample deposited at $3 \mathrm{~cm}$ target to substrate distance does not reveal any excitonic feature but shows strong absorbance below $400 \mathrm{~nm}$. This is the characteristic absorbance region $(280$ to $360 \mathrm{~nm})$ for $\mathrm{CuCl}_{2}{ }^{21}$ and a good indication of the presence of the $\mathrm{CuCl}_{2}$ phase in this sample. Moreover the film has only about $50 \%$ transmittance in the visible region where as the films with $\mathrm{d}_{\mathrm{ts}} 6 \mathrm{~cm}$ and $9 \mathrm{~cm}$ show around $95 \%$ transmittance (transmittance spectra are not given here). This may be due to the presence of free copper in the film.

The PL spectrum of $\mathrm{CuCl}$ is dominated by free exciton- $\mathrm{Z}_{3}$ emission at $383 \mathrm{~nm} .{ }^{4}$ Figure 3 shows the PL spectrum of $\mathrm{CuCl}$ on $\mathrm{Si}$ deposited with $\mathrm{d}_{\mathrm{ts}}$ of $6 \mathrm{~cm}$ taken at $10 \mathrm{~K}$. This emission is also observed in the room temperature measurements as the binding energy of the $Z_{3}$ exciton is very large. Since there is self absorption, the $Z_{3}$ emission peak is shifted to lower energy side comparing to the exciton absorption peak. The presence of the $\mathrm{Z}_{12}$ exciton is not observed in the emission spectra because it does not decay radiatively.

The samples deposited with $\mathrm{d}_{\mathrm{ts}}$ of $6 \mathrm{~cm}$ (i.e. those which showed the largest excitonic absorption) were post annealed in the range of 50 to $150^{\circ} \mathrm{C}$ in nitrogen atmosphere for 30 minutes to improve the crystalline quality. Figure 4(a) shows the change in intensity of (111) peak in the XRD spectra and the $\mathrm{Z}_{3}$ exciton peak in the absorbance spectra for the change in annealing temperatures. A very similar trend is observed in both the cases, with a gradual increase in the peak intensity up to $75^{\circ} \mathrm{C}$ and then decrease for further increase in the temperature. The reason for decrease in peak intensities beyond $75^{\circ} \mathrm{C}$ is not clear.

The correlation between intensities of XRD-(111) peak and $Z_{3}$ exciton peak is also plotted and depicted in figure 4(b) The observed linear relationship between the crystallinity and the optoelectronic characteristic shows that the excitonic absorption is closely related to the degree of disorder of the crystal. This is not unexpected since any grain boundary disorder is likely to produce alternative paths for generation and recombination. 

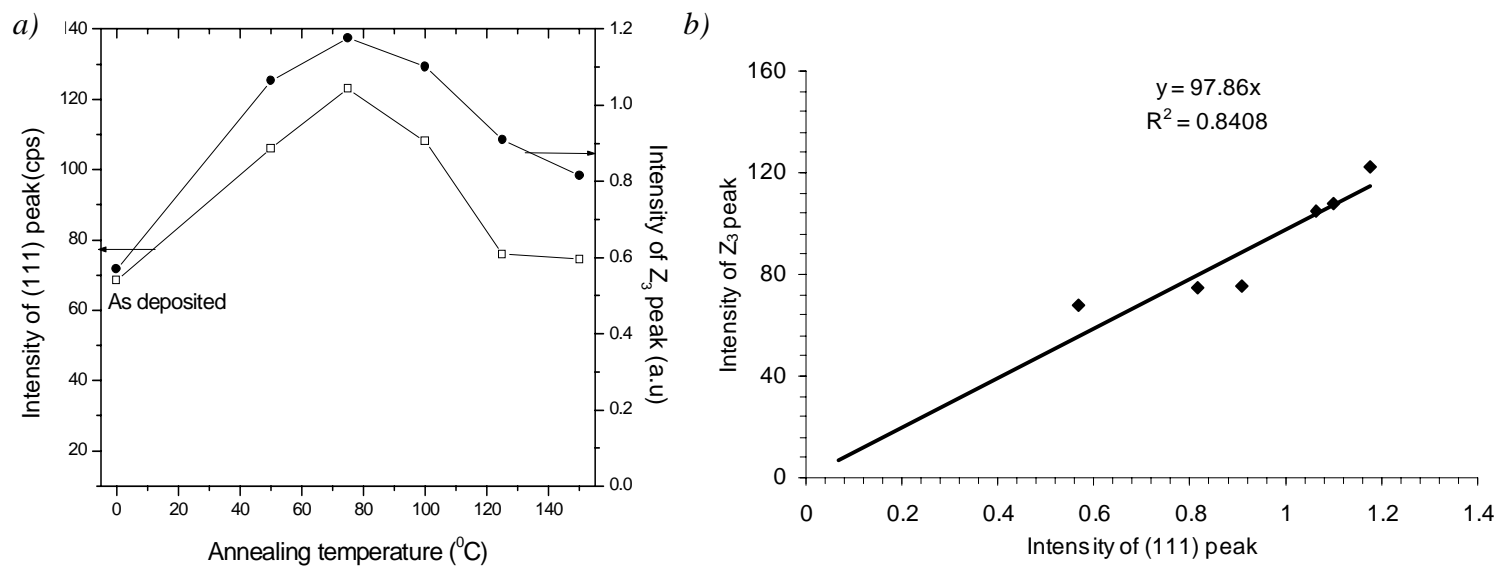

Figure 4: a) Variation of the intensity of (111) peak and $Z_{3}$ peak with annealing temperature b) Correlation between (111) XRD peak and $Z_{3}$ peak in the variation with annealing temperature

a)

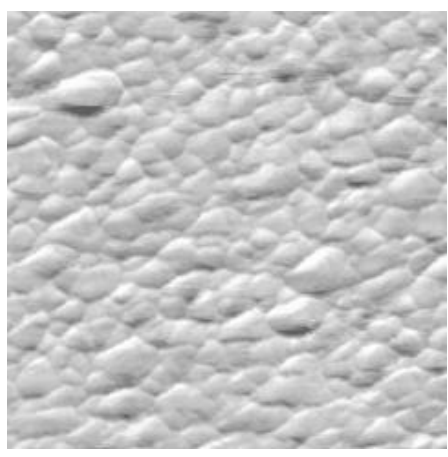

b)

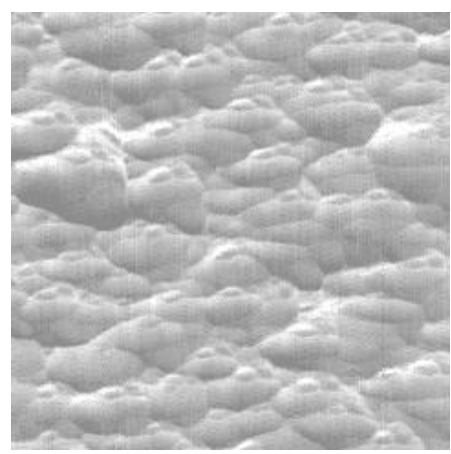

Figure 5: AFM topograph of a) as deposited b) Annealed (75 deg) CuCl on glass - Scan size $1.41 \times 1.41 \mu \mathrm{m}$

The orientation of $\mathrm{CuCl}$ crystallites on glass is also evident in the AFM topographs from the appearance of triangular crystallites of (111) faceting. These facets are similar to those reported by A.Yanase and Y.Segawa. ${ }^{7}$ Figure 5 shows the AFM topographs of the as-deposited and annealed $\mathrm{CuCl}$ films. The average crystallite size of the as-deposited sample increases from 15 to $30 \mathrm{~nm}$ due to post-annealing at $75^{\circ} \mathrm{C}$ for 30 minutes.

\section{CONCLUSIONS}

$\mathrm{CuCl}$ thin films were successfully grown by the RF magnetron sputtering technique. The effects of deposition and post annealing parameters on the film properties such as composition, micro structure, UV-Vis and photoluminescence spectra were investigated. It was found that, approximately stoichiometric $\mathrm{CuCl}$ thin films could be deposited with a strongly oriented (111) texture perpendicular to the substrate if the substrates were far enough away from the target such that the sputtered particles had lost some of their initial energy before depositing. There was strong UV absorption at room temperature from the $Z_{12}$ and $Z_{3}$ excitons and intense emission from $Z_{3}$ excitons in the PL spectra at room temperature and low temperatures. The crystalline quality was increased by post annealing at $75^{\circ} \mathrm{C}$ in nitrogen atmosphere. There was a strong correlation observed between the crystalline quality as determined by the intensity of (111) peak and the intensity of the $Z_{12}$ exciton peak in the absorbance spectra. 


\section{REFERENCES}

1. Guha S \& Bojarczuk, N.A., "Ultraviolet and violet light emitting diodes on silicon” Appl. Phys. Lett., 72, 415-417 (1998).

2. Yang J.W, Lunev A, Simin G, Chitnis A, Shatalov M, Kahn M A, Van Nostrand J E \& Gaska R, "Selective area deposited blue GaN-InGaN multiple-quantum well light emitting diodes over silicon substrates" Appl. Phys. Lett., 76, 273-275(2000).

3. Ohtani A, Stevens K.S \& Beresfor R, "Microstructure and photoluminescence of GaN grown on Si(111) by plasmaassisted molecular beam epitaxy" Appl. Phys. Lett., 65, 61-63(1994).

4. Nakayama M, Ichida $\mathrm{H} \&$ Nishimura $\mathrm{H}$, "Bound-biexciton photoluminescence in $\mathrm{CuCl}$ thin films grown by vacuum deposition” J. Phys.: Condens. Matter., 11, 7653-7662 (1999).

5. Chen W, Dumas M, Ahsan S, Kahn A, Duke C. B \& Patton A, "Epitaxial growth and characterization of $\mathrm{CuCl}(110) / \mathrm{GaP}(110)$ "J. Vac. Sci. \& Technol. A: Vacuum, Surfaces, and Films, 10, 2071-2076(1992).

6. Yanase A \& Segawa Y, "Nucleation and morphology evolution in the epitaxial growth of $\mathrm{CuCl}$ on $\mathrm{MgO}(001)$ and $\mathrm{CaF}_{2}(111)$ " Surf. Sci., 357-358,885-890(1996).

7. Yanase A \& Segawa Y, "Nucleation from ionic molecules in Stranski-Krastanov growth of $\mathrm{CuCl}$ on $\mathrm{MgO}(001)$ " App. Surf. Sci., 130-132, 566-571(1998).

8. Vanagas E, Brinkmann D, Kudrna J, Crégut O, Gilliot P, Tomasiunas R \& Hönerlage B, "Scattering and dephasing of excitonic polaritons in CuCl” J. Phys.: Condens. Matter., 14, 3627-3639(2002).

9. Williams R.S, Shuh D.K, \& Segawa Y, “Growth and luminescence spectroscopy of a CuCl quantum well structure", J. Vac. Sci. \& Technol. A: Vacuum, Surfaces, and Films,6,1950-1952(1988).

10. Olbright G. R. \& Peyghamberian N, "Epitaxial growth and X-ray diffraction analysis of single-crystal thin films of CuCl" Solid State Commun.,58, 333-411(1986).

11. Nishida N, Saiki K \& Koma A, "Heteroepitaxy of CuCl on GaAs and Si substrates" Surf. Sci. 324, 149-158(1995).

12. O'Reilly L, Natarajan G, McNally P.J, Cameron D, Lucas O.F, Martinez-Rosas M, Bradley L \& Reader A. "Growth and characterisation of wide-bandgap, I-VII optoelectronic materials on silicon” J. Mater. Sci.: Mater. Electron., submitted.

13. Tanaka T, Kawabata K, \& Hirose N, "Transparent, conductive CuI films prepared by rf-dc coupled magnetron sputtering" Thin Sol. Films, 281-282,179-181(1996).

14. Seguin J.-L, Bendahan M, Lollmun G, Pasquinelli M \& Knauth P, "Preparation of thin films of copper(I) bromide by r.f. sputtering" Thin Sol. Films, 323,31-36 (1998).

15. Yamamura Y \& Ishida M, "Monte Carlo simulation of the thermalization of sputtered atoms and reflected atoms in the magnetron sputtering discharge" J. Vac. Sci. Technol. A 13, 101-112(1995).

16. Westwood W. D, "Calculation of deposition rates in diode sputtering systems" J. Vac. Sci. Technol, 15, 1-9(1978).

17. http://inorganic.chemistry.pu.edu.tw/first/New/L4/A.html

18. Goldmann A, "Band Structure and Optical Properties of Tetrahedrally Coordinated Cu- and Ag-Halides" Phys.Stat.Sol.(b) 81,9-47(1977).

19. Han W.-T \& Yoon Y.K, "Observation of two $\mathrm{Z}_{3}$ exciton resonances in CuCl-doped non-linear optical glass"J.NonCryst.Solids, 196, 84-89(1996).

20. Sasai J, Tanaka K \& Hirao K, "Preparation and second-order nonlinear optical properties of CuCl nanocrystaldoped glass films" Scripta. Mater. 44, 1225-1228(2001).

21. Hougen J.T, Leroi G.E, \& James T.C, “Application of Ligand Field Theory to the Electronic Spectra of Gaseous $\mathrm{CuCl}_{2}, \mathrm{NiCl}_{2}$, and $\mathrm{CoCl}_{2}$ ” J. Chem. Phys, 34, 1670-1677(1961). 